\title{
Covid-19 Pandemi Dönemindeki Acil Servis Başvurularında Ürolojik Hastalıkların Sıklığı ve Aciliyet Durumuna Göre Dağılımı
}

\section{The Frequency and Distribution of Urological Diseases in Emergency Service Admissions During Covid-19 Pandemia Period}

iD Erman Ceyhan, iD Keziban Uçar Karabulut

${ }^{1}$ Başkent Üniversitesi Konya Uygulama ve Araştırma Merkezi, Üroloji Anabilim Dalı

${ }^{2}$ Başkent Üniversitesi Konya Uygulama ve Araştırma Merkezi, Acil Tıp Anabilim Dalı

$\ddot{\mathrm{O} z}$

Amaç: Çalışmamızda pandemi dönemi ve öncesinde, ürolojik şikayetlerle acil servise başvuran hastaların sıklığı ve aciliyet durumuna göre dağılımları incelenmiştir.

Gereç ve Yöntem: Çalışmamıza ülkemizde COVID-19 pandemisinin başladığı ve sıkı kısıtlamaların uygulandığı 11 Mart 2020 -1 Haziran 2020 tarihleri arasında acil servise ürolojik şikayetlerle başvuran erişkin hastalar ( $\mathrm{n}=217)$ ve 2019 yılındaki aynı tarih aralığında acil servise başvuran hastalar ( $\mathrm{n}=249)$ dahil edildi. Hastaların demografik verileri, başvuru tanıları, aynı şikayetler ile acil ve üroloji polikliniklerine başvuru sıklıkları, tedavileri ve triyaj kategorileri değerlendirildi.

Bulgular : Hastaların tanılarına göre dağılımları; \%60,1(n=280) idrar yolu enfeksiyonu, \%20(n=93) renal kolik, \%13,9(n=65) üriner sistem taş hastalığı, \%4,1(n=19) idrar retansiyonu, $\% 1,1(\mathrm{n}=5)$ hematüri, $\% 0,6(\mathrm{n}=3)$ orşit, $\% 0,2(\mathrm{n}=1)$ skrotal yaralanma olarak bulundu. $71(\% 15,2)$ hasta acil servis başvurusu sonrasında üroloji polikliniğine başvurdu. 24(\%5,2) hastanın acil servise tekrarlayan bașvurusu oldu. Hastaların aciliyet durumlarına göre dağılımlarında 2019(sarı alan n=193, yeșil alan n=56) ve pandemi dönemi(sarı alan n=156, yeșil alan $\mathrm{n}=61)$ arasında anlamlı fark izlenmedi $(\mathrm{p}=0,163)$. Acile başvuran hastalar arasında yıllara göre yaş( $(\mathrm{p}=0,348)$ ve cinsiyet $(\mathrm{p}=0,120)$ açısından fark bulunmadı. Üroloji polikliniğine ve acil servise yapılan tekrarlayan başvurularda 2019 yılı ile pandemi dönemi arasında anlamlı fark izlenmedi( $\mathrm{p}=0,604$ ve $\mathrm{p}=0,234)$. Üroloji polikliniğine başvurular 2019 ve 2020 'de benzer oranda gözlendi( $(\mathrm{p}=0,809)$. Hastaların tanılarına göre dağılımları 2019 yılı ve 2020 yılı için farklılık göstermedi(p=0,386). Hastaların yıllara göre tedavi ihtiyaçlarındaki dağılımlar incelendiğinde, 2019 yılıyla 2020 yılı arasında istatistiksel olarak anlamlı farklılık bulunmadı ( $\mathrm{p}=1,000)$.

Sonuç : Acil servise ürolojik şikayetlerle başvuran hastaların büyük çoğunluğunu idrar yolu enfeksiyonu geçiren hastalar ve taş hastaları oluşturmaktadır. COVID-19 pandemisi gibi riskli ve yoğun kısıtlamaların olduğu bir dönemde bile hastaların ürolojik hastalıkları sebebiyle acil servise başvurma oranları değişmemiştir.

Anahtar kelimeler: COVID-19; hasta başvurusu; pandemi; acil servis; idrar yolu enfeksiyonu; üriner sistem taş hastalığı

Abstract

Objective : We assessed the frequency and urgency of patients who admit to emergency room (ER) with urologic complaints during and before pandemia.

Materials and Methods : Patients(n=217) who admitted to ER with urologic complaints between March 11-June 01, 2020 during strict regulations in Turkey and patients(n=249) who admitted during the same period in 2019 included in the study. Patients' demographics, diagnosis, frequency of admission to the ER and urology clinic(UC), treatments and triage codes were assessed.

Results : Diagnosis of patients were $60.1 \%(\mathrm{n}=280)$ urinary tract infection, $20 \%(\mathrm{n}=93)$ renal colic, $13.9 \%(\mathrm{n}=65)$ urinary calculus, $4.1 \%(\mathrm{n}=19)$ urinary retension, $1.1 \%(\mathrm{n}=5)$ hematuria, $0.6 \%(n=3)$ orchitis, and $0.2 \%(n=1)$ scrotal trauma. $24(5.2 \%)$ patients had repetitive admissions to ER. Distribution of patients according to class of urgency were similar between 2019(yellow zone $n=193$, green zone $n=56$ ) and 2020(yellow zone $n=156$, green zone $n=61, p=0.163$ ). There was no significant difference between patients who admitted to ER in 2019 and 2020 regarding patients age $(\mathrm{p}=0.348)$ and gender $(\mathrm{p}=0.120)$. Frequency of repetitive admissions to the $\mathrm{UC}$ and ER were similar between 2019 and $2020(\mathrm{p}=0.604 \mathrm{vs} \mathrm{p}=0.234)$. Rate of admission to the UC was similar in 2019 and 2020 ( $\mathrm{p}=0.809$ ). Also distiribution of diagnosis was similar in 2019 and 2020 ( $\mathrm{p}=0.386$ ). There was no difference between 2019 and 2020 regarding administered treatments $(\mathrm{p}=1.000)$.

Conclusions : The vast majority of patients presenting to the ER with urological complaints were patients with urinary tract infections and urinary stone disease. Even in a risky period like COVID-19 pandemia and despite strict regulations, patients' admission rate to ER with their urological complaints didn't change.

Key words: COVID-19; patient admission; pandemics; emergency service; urinary tract infection; urinary calculi

16. Ulusal Acil Tip Kongresinde online olarak sunulmuştur

Yazışma Adresi: Erman Ceyhan, FEBU, Başkent Üniversitesi Konya Uygulama ve Araştırma Merkezi, Üroloji Anabilim Dalı, Hocacihan Mah. Saray Cad. No: 1, 42080 Selcuklu, Konya / Turkey

E-Posta: erman_ceyhan@yahoo.com

Alınma tarihi: 05.01.2021 / Kabul tarihi: 03.03.2021 / Yayımlanma tarihi: 20.09.2021

Pandemide Ürolojik Hastalıklar ve Acil Başvuruları - Ceyhan ve Uçar

Karabulut

Genel Tip Derg 2021;31(3)276-280 
2019 yılında Çin'de tanımlanan Şiddetli Akut Solunum Yolu Sendromu Koronavirüs 2 (SARS-CoV-2) virüsü ile meydana gelen yeni korona virüs hastalığı (COVID-19) tanımlanmış ve enfeksiyon kısa sürede tüm dünyaya yayılarak pandemiye neden olmuştur (1). Dünya Sağlik Örgütü'nün COVID-19 salgınını pandemi ilan ettiği ve Türkiye'de ilk COVID-19 vakasının bildirildiği 11 Mart 2020 tarihinden itibaren, ülkemizde Türkiye Cumhuriyeti Sağlık Bakanlığı ve Bilim Kurulu önerileri ile sıkı kısıtlamalar uygulanmaya başlanmıştır.

Etkin tedavi protokolü belirlenemeyen ve birçok ölüme neden olan bu yeni tip hastalığın önüne geçebilmek ve sağlık sistemi üzerine binen yükü azaltmak için ülke yönetimleri ve sağlık hizmeti veren hastaneler çalışma düzenlerinde çeşitli değişiklikleri hayata geçirdiler $(2,3)$. Hastanelerin birçoğu pandemi hastanesi haline getirildi ve çoğu sağlık kuruluşunda elektif cerrahiler duraklatıldı.

COVID-19 pandemisinde acil servisler tüm dünyada ilk başvuru basamağı olarak büyük yük altında kalmıştır. Acil servislere salgın ilişkili başvurular artarken, diğer tüm hastalıklara bağlı başvurularda belirgin azalma gözlenmiştir (3-6). Miyokard infarktüsü, pulmoner emboli, apandisit gibi acil müdahale gerektiren ve hayatı tehdit edebilecek hastalıklara bağlı başvuruların azaldığ bile literatürde bildirilmiştir $(4,7)$. Ürolojik hastalıklara bağlı acil servis başvurularında \%76,9'a varan oranlarda düşme olduğu rapor edilmiştir $(8,9)$.

Bu çalışmada 2020 y1lı pandemi döneminde, salgın olmayan 2019 yılına göre hastanemiz acil servisine ürolojik şikayetlerle yapılan başvurularda azalma olup olmadığı ve başvuruların tanılara ve aciliyet durumlarına göre dağılımları incelenmiştir.

\section{Gereç ve Yöntem}

Çalışmaya ülkemizde COVID-19 pandemisinin başladığ 1 ve sıkı kısıtlamaların uygulandığ 11 Mart 2020 - 1 Haziran 2020 tarihleri arasında ürolojik şikayetlerle acil servise başvuran 217 hasta ve kontrol grubu olarak 11 Mart 2019 - 1 Haziran 2019 tarihlerinde ürolojik şikayetlerle acil servise başvuran 249 hasta dahil edildi. Çalışma kapsamında belirlenen tarihlerde acil servise başvuran tüm hastalar içerisinden tanılarına göre ürolojik hastalıkları olan 466 erişkin hasta retrospektif olarak değerlendirildi. Çocuk hastalar $(<18$ yaş), ürolojik şikayeti olmayan hastalar ve tanı ilişkili verileri eksik olan hastalar çalışma dışı bırakıldı.

Hastaların demografik verileri, başvuru tanıları, başvuru sıklıkları, tedavileri ve aciliyet durumları (triyaj kategorisi) değerlendirildi. Belirtilen tarihlerde acil servise başvuran hastaların aynı şikayet ile acil servise ve üroloji polikliniğine tekrarlayan başvuru sayıları ayrı ayrı kayıt edildi. Klinik ve radyolojik bulgular ile hastalar değerlendirildiğinde, taş lokalizasyonu belirlenemeyen hastalar ICD10 tanı sınıflamasına göre N23.0 (Renal kolik) tanısı ile incelemeye alındı. Tanılara göre ICD-10 tanı kodu N20.0 (Böbrek taş1), N20.1 (Üreter taş1), N20.2 (Böbrek taş1, üreter taş1 ile birlikte), N20.9 (Üriner taşı, tanımlanmamış) ve N23.0 (Renal kolik, tanımlanmamış) olan hastalar üriner sistem taş hastalığı olarak sınıflandırıldı. Tanı kodu N30.0 (Akut sistit) ve N39.0 (Üriner sistem enfeksiyonu, yeri tanımlanmamış) olan hastalar ise idrar yolu enfeksiyonu (IYE) olarak sınıflandırıldı. Hastalara konulan diğer tanılar R33.0 (İdrar retansiyonu), R31.0 (Hematüri, tanımlanmamış), N45.9 (Orşit, epididimit, ve epididimo-orşit, apsesiz) ve S31.3 (Skrotum ve testis açık yarası) olarak kayıt edildi.

Bu çalışma Başkent Üniversitesi Tıp ve Sağlık Bilimleri Araştırma Kurulu (Proje no: KA20/296) ve T.C. Sağlik Bakanlığı (Onay No: 2020-07-01T10_16_08) tarafindan onaylanmıştır.

\section{İstatistiksel analiz}

İstatistiksel analizler IBM SPSS Statistics v.23® (IBM Corp., Armonk, N.Y., USA) programında yapıldı. Sürekli değişkenler ortalama \pm standart sapma olarak, kategorik değişkenler sayı ve yüzde ile gösterildi. Normal dağılıma uymayan değişkenlerin analizinde Mann- Whitney U testi kullanıldı. Kategorik değişkenlerin karşılaştırılmasında Ki-kare testi kullanıldı. $\mathrm{p}<0,05$ değeri istatistiksel olarak anlamlı kabul edildi.

\section{Bulgular}

Tüm hastaların ( $\mathrm{n}=466)$ yaş ortalamas1 45,9 $\pm 17,5$ yıldı. Tüm hastalar için erkek kadın oranı 214 / 252 idi. Tüm hastalar tanılarına göre sınıflandırıldığında ürolojik şikayet ile acil servise en sık başvuru sebebinin IYE $(\% 60,1)$ olduğu, ikinci sıklıkta ise üriner sistem taş hastalığının $(\% 33,9)$ geldiği görüldü. Acile başvuran hastaların $\% 15,2$ (71/466)'sinin daha sonra üroloji polikliniğine başvurduğu görüldü (min-mak: 1-4 kez). Tüm hastaların \%5,2 (24/466)'sinin aynı şikayetlerle tekrar acil servise başvurduğu tespit edildi (min-mak: 1-3 kez). Hastalar triyaj kategorilerine göre incelendiğinde hastaların $\% 74,9$ (349/466)'unun sarı alanda, \%25,1 (117/466)'inin yeşil alanda değerlendirildiği belirlendi. 2019 yılında acil servise yapılan toplam 5715 başvurudan $260(\% 4,5)$ başvurunun ürolojik şikayetlerle yapıldığ 1 görüldü. 2020 yılında ise 3676 acil servis başvurusundan $233(\% 6,3)$ başvurunun ürolojik şikayetlerle yapılmış olduğu görüldü. Yıllara göre tüm başvurular içerisindeki ürolojik şikayetlerle başvuru oranı istatistiksel olarak anlamlı derecede farklıydı $(\mathrm{p}=0,000)$.

Yıllara göre acil servis başvuruları incelendiğinde 2020 yılında ürolojik şikayetlerle acil servise başvuran hasta sayısında 2019 yılına göre \%12,8 azalma olduğu görüldü. 2019 ve 2020 yılları arasında hastaların yaş, cinsiyet, üroloji polikliniğine ve acil servise tekrar başvuru oranları, üroloji polikliniği ve acil servise tekrar başvuru sayıları ile triyaj kategorilerine göre dağılımları Tablo 1'de verilmiştir. Hastaların acil servise başvuru tanıları incelendiğinde sıklık sırasına göre dağılımın; üriner sistem enfeksiyonu, renal kolik, üreter taş1, akut sistit, üriner taş1, idrar retansiyonu, böbrek taşı, böbrek taş1-üreter taşı ile birlikte, hematüri, orşit epididimit epididimo-orşit, skrotum ve testis açık yarası şeklinde olduğu görüldü (Tablo 2). Sınıflandırılmamış (Tablo 2) ve sınıflandırılmış (Tablo 3) tanılara göre yıllar arasında istatistiksel olarak anlamlı fark izlenmedi ( $p>0,05)$. Ürolojik şikayetlerle başvurular içerisinde üriner sistem taş hastalığına bağlı başvurularda, pandemi döneminde önceki yıla göre $\% 6,5$ oranında bir azalma olduğu görüldü.

Pandemide Ürolojik Hastalıklar ve Acil Başvuruları - Ceyhan ve Uçar Karabulut 
Tablo 1. 2019 ve 2020 yıllarında hastaların yaş, cinsiyet, üroloji polikliniğine ve acil servise tekrar başvuru oranları, üroloji polikliniği ve acil servise tekrar başvuru sayıları ve triyaj kategorilerine göre dağılımları.

\begin{tabular}{|l|c|c|c|}
\hline Parametre & 2019 & 2020 & p değeri \\
\hline Yaş (median, min-mak) & $47(21-82)$ & $44,5(19-87)$ & 0,348 \\
\hline Cinsiyet (erkek/kadın) & $106 / 143$ & $108 / 109$ & 0,120 \\
\hline Üroloji polikliniğine başvuru oranı (\%, n) & $14,9(37 / 249)$ & $15,7(34 / 217)$ & 0,809 \\
\hline $\begin{array}{l}\text { Üroloji polikliniğine tekrar başvuru } \\
\text { sayısı (median, min-mak) }\end{array}$ & $1(1-4)$ & $1(1-4)$ & 0,604 \\
\hline Acil servise tekrar başvuru oranı (\%, n) & $4(10 / 249)$ & $6,5(14 / 217)$ & 0,235 \\
\hline $\begin{array}{l}\text { Acil servise tekrar başvuru sayısı } \\
\text { (median, min-mak) }\end{array}$ & $1(1-3)$ & $1(1-3)$ & 0,234 \\
\hline Triyaj kategorisi (sarı alan/yeşil alan) & $193 / 56$ & $156 / 61$ & 0,163 \\
\hline
\end{tabular}

Tablo 2. 2019 ve 2020 yıllarında hastaların acil servise başvuru tanılarına göre dağılımı $(\mathrm{p}=0,386)$

\begin{tabular}{|l|c|c|c|}
\hline Tan1 (ICD-10) & $2019(\mathrm{n}, \%)$ & $2020(\mathrm{n}, \%)$ & Toplam \\
\hline N39.0 & $127(\% 49,6)$ & $129(\% 50,4)$ & $256(\% 100)$ \\
\hline N23.0 & $55(\% 59,1)$ & $38(\% 40,9)$ & $93(\% 100)$ \\
\hline N20.1 & $17(\% 60,7)$ & $11(\% 39,3)$ & $28(\% 100)$ \\
\hline N30.0 & $17(\% 70,8)$ & $7(\% 29,2)$ & $24(\% 100)$ \\
\hline N20.9 & $11(\% 57,9)$ & $8(\% 42,1)$ & $19(\% 100)$ \\
\hline R33.0 & $9(\% 47,4)$ & $10(\% 52,6)$ & $19(\% 100)$ \\
\hline N20.0 & $6(\% 66,7)$ & $3(\% 33,3)$ & $9(\% 100)$ \\
\hline N20.2 & $3(\% 33,3)$ & $6(\% 66,7)$ & $9(\% 100)$ \\
\hline R31.0 & $3(\% 60,0)$ & $2(\% 40,0)$ & $5(\% 100)$ \\
\hline N45.9 & $1(\% 33,3)$ & $2(\% 66,7)$ & $3(\% 100)$ \\
\hline S31.3 & $0(\% 0)$ & $1(\% 100)$ & $1(\% 100)$ \\
\hline
\end{tabular}

Tablo 3. 2019 ve 2020 yıllarında acil servis başvurularının sınıflandırılmış tanılara göre dağılımı $(\mathrm{p}=0,292)$

\begin{tabular}{|l|c|c|c|}
\hline Tanı & $2019(\mathrm{n}, \%)$ & $2020(\mathrm{n}, \%)$ & Toplam \\
\hline $\begin{array}{l}\text { Üriner Sistem Taş Hastalı̆ı̆ (N20.0, } \\
\text { N20.1, N20.2, N20.9, N23.0) }\end{array}$ & $92(36,9)$ & $66(30,4)$ & 158 \\
\hline IYE (N30.0, N39.0) & $144(57,8)$ & $136(62,7)$ & 280 \\
\hline Diğer (R31.0, N45.9, S31.3, R33) & $13(5,2)$ & $15(6,9)$ & 28 \\
\hline Toplam & $248(100)$ & $217(100)$ & 466 \\
\hline
\end{tabular}

Hastaların hepsine acil servis başvurusu sırasında medikal tedavi uygulandığ $1,2 / 466(\% 0,4)$ hastanın acilden hospitalize edildiği belirlendi. Hastalara üroloji tarafindan uygulanan tedaviler incelendiğinde; hospitalize edilen bir hastaya JJ-stent çıkartılması cerrahisi uygulandığı, dört hastaya üreter taşı sebebiyle endoskopik üreter taşı tedavisi yapıldı $\breve{g}$, iki hastaya üriner retansiyon sebebiyle bipolar transüretral prostat rezeksiyonu yapıldığı, bir hastanın böbrek taşı sebebiyle ekstrakorporeal şok dalga litotripsi tedavisi aldığı ve bir hastaya skrotal kesi sebebiyle kesi süturasyonu yapıldığı görüldü $(\mathrm{p}=1,000)$.

\section{Tartışma}

COVID-19 pandemisi tüm dünyada işleyen sağlık sistemleri ve hasta yönetiminde büyük değişime sebep olmuştur. Pandemi ile birlikte acil müdahale gerektiren hastalıklara yönelik sağllk hizmeti başvurularında değişim olması beklenmemiştir. Buna rağmen klinisyenler, acil müdahale gerektiren olgulara bağlı başvurularda azalma, başvuruda gecikme ve komplike hale gelmiş vaka sayılarında artma ile karşı karşıya kalmışlardır (10-12). Hastalar COVID-19 bulaşı korkusuyla şikayetlerini bekletmiş ve hastalıkları ilerlemiş olarak karşımıza gelmişlerdir (10).

COVID-19 pandemi dönemi ile ilişkili poliklinik ve hastane başvurularına yönelik yapılan retrospektif çalışmaların büyük çoğunluğunda, kontrol grubu olarak bir önceki yılın aynı tarih aralığında başvuru yapan hasta popülasyonu kullanılmıştır $(3,4,6$, 13). Bu çalışmada da literatürdeki çalışma düzenlerine benzer olarak 2019 yılı aynı dönemde acil servise başvuran hastalar kontrol grubu olarak çalışmaya dahil edildi. Kontrol grubu seçiminde Türkiye'de pandemi başlangıcı olarak kabul edilen 11 Mart 2020 tarihinden önceki dönem, hastaların COVID-19 salgınının dünyadaki seyrinden çekinerek hastane başvurularını azaltabilecekleri düşüncesiyle tercih edilmemiştir.

Literatürde poliklinik, acil servis ve hastane başvurularında pandemi döneminde belirgin azalma gözlendiği bildirilmiştir $(3,4,6)$. Başvuru sayılarındaki bu azalmanın nedeni olarak COVID-19 bulaş korkusu, kısıtlamalara bağlı erişim sorunu, azaltılan cerrahilere bağlı tekrarlayan başvuru gerekliliğinde azalma, sosyal izolasyona bağlı ishal, solunum yolu enfeksiyonlarının bulaş oranlarında azalma gibi birçok etken ileri sürülmüştür (6). Barten ve ark.'nın yaptığı bir çalışmada Hollanda'da yer alan 3 hastanenin acil servis başvuru verileri incelenmiş ve çalışmada COVID-19 ilişkili olmayan acil servis başvurularında 2019 yılı aynı döneme göre \%66 oranında azalma gözlendiği bildirilmiştir (6). Ojetti ve ark.'nın yaptığı çalışmada tüm acil servise başvurularında 2019 yılına göre \%37,6 oranında azalma ile birlikte ürogenital acillerde de belirgin azalma olduğu rapor edilmiştir. (3). Kuzey Amerika'dan bildirilen, 3219 hastanın ve 8 acil müdahale hastanesinin dahil edildiği bir çalışmada ise 2019 yılından 2020 pandemi dönemine tüm hastalıklar için yapılan başvuruların $\% 33,7$ oranında azaldığı bildirilmiştir (4). Aynı çalışmada hayatı tehdit eden ST-segment yükselmeli miyokard enfarktüsü (\%23 oranında azalma), serebrovasküler olay ( $\% 29,1$ oranında azalma) gibi hastalıklara bağlı başvurularda azalma izlenirken, taş hastalığına bağ $l_{1}$ başvurularda \%42,2 oranında bir azalma rapor edilmiştir. Acil servise üriner sistem taş hastalığı sebebiyle yapılan başvuruların incelendiği bir diğer çalışmada; 2019 y1lına göre 2020 yılı pandemi döneminde $\% 48,8$ 'lik bir azalma olduğu ortaya konmuştur (11). Gallioli ve ark. ise yaptıkları çalışmada, İtalya' da uygulanan sıkı kısıtlama döneminde 2019 y1lına göre acil servise başvuran üroloji hastalarında \%76,9'luk azalma ile literatürdeki en yüksek düşüşü rapor etmişlerdir (9). Bir başka çalışmada, ürolojiye özel acil servise yapılan başvurularda bir önceki yıla göre pandemi döneminde $\% 46,4$ oranında düşme olduğu bildirilmiştir (8). Çalışmamızda ise acil servise başvuran tüm hasta başvurularında $\% 35,6^{\prime}$ lık bir azalma izlenirken, ürolojik şikayetlerle başvuran hastalarda (\%12,8 azalma) ve üriner sistem taş hastalığına bağlı başvurularda (\%6,5 azalma) minimal bir azalma olduğu görülmüştür.

Pandemi yönetiminde sağlı sistemine binen yükün azaltılması için 
gereksiz hastane başvurularının önlenmesine, elektif muayene ve cerrahilerin ertelenmesine yönelik birçok algoritma yayınlanmıştır. Ülkelerin resmi kurumlarının yanı sıra Avrupa Üroloji Derneği (EAU) gibi otoriteler ve çeşitli yazarlar pandemi yönetimi ile ilgili kılavuzlar yayınlamış ve bu dönemde üroloji hastalarının yönetimine yönelik öneriler sunmuşlardır (14-16). Akılcı bir yaklaşım hastaların kendi kendilerine triyaj yapmaları ve/veya hastaneye gelmeden önce telefon yoluyla triyaj yapılması yolu ile gereksiz hastane başvurularının önlenmesi yönünde olmuştur $(14,17)$. Pandemi döneminde bulaş riski sebebiyle hastaların acil servise daha az oranda başvurması ve telefon yoluyla bilgi alarak ayaktan hasta polikliniklerine daha çok başvurmaları beklenmiştir. Fakat çalışmamızda ürolojik hastalıkları olan hastaların acil servise başvuru oranları, acil servis muayenesi sonrasında üroloji polikliniğine başvuru oranları, acile ve üroloji polikliniğine tekrarlayan başvuruları 2019 ve 2020 yılları arasında farklılık göstermemiştir (sırasılyla $\mathrm{p}=0,235, \mathrm{p}=0,809, \mathrm{p}=0,234$ ve $\mathrm{p}=0,604$ ). Hastanemize başvuran üroloji hastalarının, pandemi sebebiyle tutumlarını değiştirmedikleri gözlenmiştir.

Çalışmamızda 2019 yılı ile pandemi dönemi arasında acil servise ürolojik şikayetlerle başvuran hasta popülasyonlarında yaş ve triyaj kategorisi açısından anlamlı fark izlenmemiştir $(p=0,348$ ve $\mathrm{p}=0,163$ ). Acil servise başvuran tüm hastaların değerlendirildiği Ojetti ve ark.'nın çalışmasında da benzer şekilde yaş açısından 2019 ve pandemi dönemi arasında anlamlı fark bulunmamıştır, fakat triyaj kategorisinde ve daha önemsiz şikayetlerle olan başvurularda azalma görüldüğü bildirilmiştir (3). Acil servise başvuran üroloji hastalarının değerlendirildiği Gallioli ve ark.'nın çalışmasında, 2019 yılı ile 2020 kısıtlama dönemi hasta popülasyonu arasında yaş ve cinsiyet açısından istatistiksel anlamlı fark bulunmamıştır ( $p>0,05)$ (9). Yine aynı çalışmada bizim sonuçlarımıza benzer şekilde, üroloji hastalarının acil servis triyaj kategorileri açısından 2019 yılı ile 2020 y1lı arasında belirgin fark gösterilmemiştir $(p>0,05)$.

Madanelo ve ark.'nın yaptığı çalışmada, ürolojiye özel acil servise yapılan hasta başvuruları incelenmiş ve 2019 ile 2020 pandemi döneminde yapılan en sık başvuru nedenlerinin hematüri, renal kolik ve üriner sistem enfeksiyonu olduğu bildirilmiştir (8). Aynı çalışmada pandemi döneminde akut sistite bağlı başvuruların daha az olduğu görülmüş̧ür. Bizim çalışmamızda yine idrar yolu enfeksiyonu, renal kolik ve üriner sistem taş hastalığ 1 en s1k başvuru nedenleri olarak bulunmuştur. Çalışmamızda hematüri ile başvuran hasta sayısı bu tanılara göre daha az oranda tespit edilmiştir. 2542 hastanın değerlendirildiği çok merkezli bir çalışmada, acil servise ürolojik şikayetlerle yapılan başvuruların bizim serimize benzer olarak en sık idrar yolu enfeksiyonu ve renal kolik nedeniyle olduğu bildirilmiştir (18). Antonucci ve ark.'nın 304 hasta üzerinde yaptığı retrospektif analizde, acil servise ürolitiyazis sebebiyle yapılan başvurular incelenmiştir (11). Çalışmada ürolitiyazis ile acil servise yapılan başvurularda belirgin düşme olduğu gösterilirken, başvuru yapan hastaların daha komplike halde başvurduğu, daha sı hospitalizasyon gerektirdikleri ve daha sık erken taş cerrahisine gittikleri bildirilmiştir. Çalışmamızda, acil servise başvuru sonrasında hastalara uygulanan tedaviler açısından 2019 ve 2020 yılları arasında istatistiksel anlamlı fark izlenmemiştir $(\mathrm{p}=1,00)$. Benzer şekilde Madanelo ve ark.'nın yaptığı çalışmada, üroloji acil servisine yapılan başvurular sonrasında acil cerrahi uygulanan hasta oranları 2019 ve 2020 y1lı arası benzer olarak bulunmuştur (8).

İdrar yolu enfeksiyonu ve üriner sistem taş hastalığı, hastalarda şiddetli ağrı ve rahatsızlık hissine sebep olmaları sebebiyle acil servise başvuru oranlarının yüksek olduğu ürolojik hastalıklardır. Miyokard infarktüsü, serebrovasküler olay, apandisit gibi hayatı tehdit eden hastalıklara bağlı acil servis başvurularının bile azaldığı bu dönemde, hastanemiz acil servisine ürolojik şikayetler ile yapılan başvurularda bir önceki yıl ile karşılaştırıldığında anlamlı bir azalma gözlenmemiştir $(4,19)$. Bu durumun nedeni olarak ilk aşamada hastanemizin özel hastane kategorisinde olması ve il içi hasta dağılımının özel hastanelere kaymış olabileceği düşünülebilir. Fakat literatürde özel hastane olarak hizmet veren hastane acil servisine yapılan başvurularda pandemi döneminde \%75 oranında azalma olduğu bildirilmiştir (20).

$\mathrm{Bu}$ çalışmanın temel kısıtlılığı, retrospektif yöntemle yürütülmüş olmasıdır. Hızlı başlangıçlı ve seyri tahmin edilemeyen COVID-19 pandemi süreci ile ilgili sistematik, prospektif çalışmaların yürütülmesi ise her zaman uygulanabilir değildir. Çalışmamızın bir diğer kısıtlılığı ise görece düşük hasta sayısı ve tek merkezli gerçekleştirilmiş olmasıdır. Çok merkezli ve yüksek hacimli merkezlerin katılımıyla yapılabilecek çalışmalarca, ülkemizdeki ürolojik hastaların acil servise başvuru oranları ve tıbbi tedaviye erişim tutumları hakkında daha fazla bilgiye ulaşılabilir.

\section{Sonuç}

COVID-19 pandemi döneminde acil servise ürolojik şikayetler ile yapılan başvuruların belirgin azaldığını gösteren yabancı literatürden farklı olarak çalışmamızda, hastanemiz acil servisine yapılan ürolojik başvuruların pandemiden etkilenmediğini ortaya konmuştur. $\mathrm{Bu}$ durumun hastaların özel hastanelerin daha temiz olacağı ve hasta yoğunluğunun daha az olacağı düşüncesi ile daha çok tercih etmesi ve renal kolik gibi ürolojik şikayetlerin şiddetli ağrıya sebep olarak hastaların daha sık tıbbi tedaviye başvurmalarına neden olması sebebiyle ortaya çıktığını düşünmekteyiz. Özellikle idrar yolu enfeksiyonu ve üriner sistem taş hastalığı ürolojik hastalıklar arasında acil servislere en s1k başvuru sebepleridir. Bu hastalılar sebebiyle hastalar ciddi pandemi kısıtlamalarına rağmen hastalığın belirli bir evresinde tıbbi müdahale ihtiyacı duymuşlardır ve acil servise başvurmuşlardır. Pandemi döneminde acil servise yapılan tüm başvurularda belirgin azlama olmasına rağmen ürolojik hastalıklara bağlı başvurularda belirgin azalma izlenmemiştir.

\section{Kaynaklar}

1.Zhu N, Zhang D, Wang W, Li X, Yang B, Song J, et al. A novel coronavirus from patients with pneumonia in China, 2019. N Engl J Med. 2020.

2.Westhofen T, Magistro G, Lennartz S, Casuscelli J, Stief C, Rodler S. Confronting hidden COVID-19 burden: a telemedical solution for elective urological outpatient clinics. Infection. 2020;48(6):935-9.

3.Ojetti V, Covino M, Brigida M, Petruzziello C, Saviano A, Migneco A, et al. NonCOVID Diseases during the Pandemic: Where Have All Other Emergencies Gone? Medicina. 2020;56(10):512.

4.Oseran AS, Nash D, Kim C, Moisuk S, Lai P-Y, Pyhtila J, et al. Changes in hospital admissions for urgent conditions during COVID-19 pandemic. Am J Manag Care. 2020;26(8):327-8

5.Wongtanasarasin W, Srisawang T, Yothiya W, Phinyo P. Impact of national lockdown towards emergency department visits and admission rates during the COVID-19 pandemic in Thailand: A hospital-based study. Emerg Med Australas. 2020.

6.Barten DG, Latten GH, Van Osch FH. Reduced emergency department utilization during the early phase of the COVID-19 pandemic: viral fear or lockdown effect? Disaster Med Public Health Prep. 2020:1-4.

Pandemide Ürolojik Hastalıklar ve Acil Başvuruları - Ceyhan ve Uçar Karabulut 
7.Bugger H, Gollmer J, Pregartner G, Wünsch G, Berghold A, Zirlik A, et al. Complications and mortality of cardiovascular emergency admissions during COVID-19 associated restrictive measures. PLoS One. 2020;15(9):e0239801.

8.Madanelo M, Ferreira C, Nunes-Carneiro D, Pinto A, Rocha MA, Correia J, et al. The impact of the coronavirus disease 2019 pandemic on the utilisation of emergency urological services. BJU international. 2020;126(2):256-8

9.Gallioli A, Albo G, Lievore E, Boeri L, Longo F, Spinelli MG, et al. How the COVID-19 Wave Changed Emergency Urology: Results From an Academic Tertiary Referral Hospital in the Epicentre of the Italian Red Zone. Urology. 2020

10.Kumaira Fonseca M, Trindade EN, Costa Filho OP, Nácul MP, Seabra AP. Impact of COVID-19 Outbreak on the Emergency Presentation of Acute Appendicitis. The American Surgeon. 2020:0003134820972098.

11.Antonucci M, Recupero S, Marzio V, De Dominicis M, Pinto F, Foschi N, et al. E impacto de la COVID-19 en las admisiones al servicio de urgencias, hospitalizaciones y manejo clínico de la urolitiasis en el centro de Italia: análisis multicéntrico. Actas Urol Esp. 2020;44(9):611-6.

12.Pessoa-Amorim G, Camm CF, Gajendragadkar P, De Maria GL, Arsac C, Laroche C, et al. Admission of patients with STEMI since the outbreak of the COVID-19 pandemic A survey by the European Society of Cardiology. European Heart Journal-Quality of Care and Clinical Outcomes. 2020

13.Bozkurt O, Sen V, Irer B, Sagnak L, Onal B, Tanidir Y, et al. Nation-wide analysis of the impact of Covid-19 pandemic on daily urology practice in Turkey. Int J Clin Pract. 2020:e13735

14. Simonato A, Giannarini G, Abrate A, Bartoletti R, Crestani A, De Nunzio C, et al Pathways for urology patients during the COVID-19 pandemic. Minerva urologica e nefrologica $=$ The Italian journal of urology and nephrology. 2020.

15.Ribal M, Cornford P, Briganti A, Knoll T, Gravas S, Babjuk M. EAU Guidelines Office Rapid Reaction Group: an organisation-wide collaborative effort to adapt the EAU guidelines recommendations to the COVID-19 era. Eur Urol. 2020;302(20):30324-9.

16.Socarrás MER, Esperto F, Bapstistussi MD, Barufaldi F, Vital MS, Papalia R, et al Endourology (Lithiasis). Management, surgical considerations and follow-up of patients in the COVID-19 era. International braz j urol. 2020;46:39-49.

17.Judson TJ, Odisho AY, Neinstein AB, Chao J, Williams A, Miller C, et al. Rapid design and implementation of an integrated patient self-triage and self-scheduling tool for COVID-19. J Am Med Inform Assoc. 2020;27(6):860-6.

18. Grasso AA, Massa G, Castelnuovo M. The Impact of COVID-19 Pandemic on Urological Emergencies: A Multicenter Experience on over 3,000 Patients. Urol Int. 2020:1-4.

19.Oikonomou E, Aznaouridis K, Barbetseas J, Charalambous G, Gastouniotis I, Fotopoulos V, et al. Hospital attendance and admission trends for cardiac diseases during the COVID-19 outbreak and lockdown in Greece. Public Health. 2020;187:115-9.

20.Bozovich GE, Alves De Lima A, Fosco M, Burgos LM, Martínez R, Dupuy De Lôme $\mathrm{R}$, et al. Daño colateral de la pandemia por COVID-19 en centros privados de salud de Argentina. Medicina (B Aires). 2020;80. 